UC-4

Issued: May 1986

\title{
MASTER
}

\section{Quantification of Neptunium by Isotope Dilution Mass Spectrometry}

D. W. Efurd

DE86 012746

\author{
J. Drake
}

F. R. Roensch

J. H. Cappis

R. E. Perrin

\section{DISCLANMER}

This report was prepared as an account of work sponsored by an agency of the United States Neither the United Sates Government nor eny agency thereof, nor any of their Government Neither the United seates or implied, or assumes any legal liability or responsiemployees, makes any warranty, cxpress or imples, of any information, apparatus, produci, or bility for the accuracy, completeness, or usefulness of any inforinge privately owned rights. Referprocess disclosed, or represents that its we wercial product, process, or service by trade name, trademark, ence herein to any specific commercial product, pronstitute or imply its endorserent, recommanufacturer, or otherwise does not necessarily constite or imply its cry thereof. The views mendation, or favoring by the United States Government or an ate or reflect those of the and opinions of authors expressed herein do not

United States Government or any agency thereof.
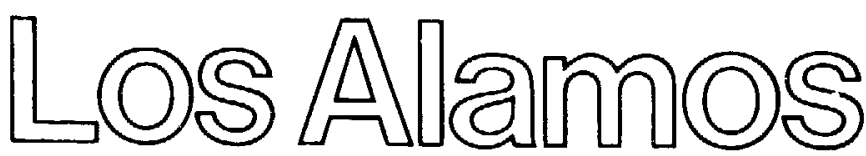


\title{
QUANTIFICATION OF NEPTUNIUM BY ISOTOPE DILUTION MASS SPECTROMETRY
}

\author{
by
}

\author{
D. W. Efurd, J. Drake, F. R. Roensch, J. H. Cappis, and R. E. Perrin
}

\begin{abstract}
A surface ionization-diffusion-type ionization source that uses a rhenium filament overplated with platinum has been developed and optimized for 0.1-ng neptunium samples. This source is capable of measuring the neptunium content of nuclear-test-debris samples to $0.15 \%$ precision at the $95 \%$ confidence level.
\end{abstract}

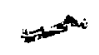

\section{INTRODUCTION}

Nuclear-test diagnostic programs require accurate and precise analysis of neptunium that has been separated from debris collected after underground detonations at the Nevada Test Site. Measurements are made on thermal ionization mass spectrometers operating in the pulse-counting mode. Sample sizes are kept as small as feasible to help minimize any radiation exposure to the separations chemist.

Originally, the separated and purified neptunium samples were loaded from aqueous solutions onto rhenium filaments for analysis. The quality of the results was degraded by scatter from ion beams produced by trace elements and by isobaric interferences from residual hydrocarbons associated with the samples.

Rec et al. ${ }^{1}$ developed a single-filament surface ionization-diffusion (SID)-type source for actinide analysis. Samples were evaporated onto a rhenium filament from a weak acid solution. Next, they were clad with a film of high-work-function rhenium by radio-frequency diode sputtering techniques. The cladding provided high ionization efficiencies and improved control over the generation of the ion beam. It limited the prompt escape of neutral atoms. It also completely dissociated molecular species so that only atomic species appeared in the mass spectrum.

Perrin et al. ${ }^{2}$ modified this SID-type ionization source. They electroplated the actinides onto rhenium filaments. Next, a thiz layer of rhenium was overplated by electrodeposition. The electrodeposition step reduced the alkali metal and hydrocarbon concentrations in the sample. However, the source suffered from two weaknesses. (1) The conditions for proper rhenium overplating and spectrometer operation were very critical. The rhenium overplate was deposited as a hydride, which was then converted to metal by decomposition in the ionization chamber of the spectrometer. The conditions for both overplating and conversion to the metal were very subjective and led to an excessive failure rate. (2) The sample reached meximum count rate before the ion beam reached maximum stability. Once the beain stabilized, the signal intensity decreased appreciably. These deficiencies of the SID source were corrected by overplating with platinum instead of rhenium. ${ }^{3,4}$ 
This report summarizes the development of the SID analysis source for neptunium using the platinum overplate. The technique was optimized for 0.1-ng samples but is useful for samples ranging from $4 \times 10^{-8}$ to $10 \mathrm{ng}$. The chemistry described in this report should be capable of separauiing trace quantities of neptunium from $100 \mathrm{~g}$ of debris.

\section{INSTRUMENTATION}

The mass spectrometer used in this study is a modified version of the 30.5 -cm-radius, $90^{\circ}$-deflection, thermal ionization instrument that was developed at the National Bureau of Standards (NBS). ${ }^{5}$ The spectrometer is designed to operate as an ultrahighvacuum instrument. Its pumping systeln consists of a mercury diffusion pump and a $140-\ell / \mathrm{s}$ ion pump. Additional purnping is achieved during analysis by filling a cold trap (located in the source housing) with liquid nitrogen. The spectrometer has been equipped with a 17-stage electron multiplier that has copper-beryllium dynodes. The front dynode is flat. The multiplier can be translated along the $\mathrm{x}$ axis for proper interception of the ion beam. Gain is set by calibration against a Faraday cup. The signal from the multiplier passes through a Shideler discriminator-amplifier that is capable of supplying a 1-V, 7-ns-wide output pulse when it is triggered by pulses from $6 \mathrm{MV}$ to $2 \mathrm{~V}$ (Ref. 6). Counts are accumulated on a $250-\mathrm{MHz}$ scaler. The dark current of the counting system is $0.05 \mathrm{cps}$; its dead time is $11 \pm 1 \mathrm{~ns}$. The system's oveiall linearity and deadtime is verified by analyzing NBS standards U-100, U-500, and U-900. The data acquisition system has been autcmated with a Hewlett-Packard $85 \mathrm{~B}$ computer.

The mass spectrometer filaments are $0.76 \mathrm{~mm}$ wide and $12 \mathrm{~mm}$ long. They are fabricated from 0.025-mm-thick, zone-refined rhenium. Before the samples are loaded, the filaments are degassed by being heated in a vacuum for $30 \mathrm{~min}$ at $2100^{\circ} \mathrm{C}$. The pressure in the degasser starts at $1 \times 10^{-6}$ torr and is reduced to about $5 \times 10^{-8}$ torr by the end of bakeout. A negative $90-\mathrm{V}$ dc potential is applied to the filaments during outgassing.

\section{PRODUCTION OF AN SID IONIZATION SOURCE WITH PLAT- INUM OVERCOATINGS}

Previous studies established that neptunium can be plated onto rhenium filaments from $\mathrm{HCl}$ that contained $\mathrm{NH}_{4} \mathrm{Cl}$. Overplates deposited from platinum DNS (dinitrato sulfato platinous acid) diluted with $1.5 \mathrm{M} \mathrm{HCl}$ produced excellent SID filaments.

Figure 1 shows the apparatus used for the electrodeposition; Figs. 2(a) and (b) show the apparatus in the plating and rinsing modes, respectively. A trough is formed by placing $6.4-\mathrm{mm}$-wide Teflon tape beneath a rhenium mass spectrometer ionization filament and over two support rods. This trough will hold $\simeq 150 \mu \ell$ of solution. The Teflon tape forms a seal and prevents electrodeposition of the neptunium on the bottom of the filament. The platinum anode is made by spot welding 0.25 -mm-diam platinum wire on a filament pin. A regulated HP-6100 dc power supply furnishes the electrolysis current. The electrode spacing is maintained at 3.2 to $3.6 \mathrm{~mm}$. If an electrode spacing less than $3.2 \mathrm{~mm}$ is used, the higher current density will destroy the electrolyte too quickly; spacings greater than $3.6 \mathrm{~mm}$ increase the plating time. The method used to produce platinum-overplated SID filaments is detailed below.

Pipette $10 \mu \ell$ of $1.5 \mathrm{M} \mathrm{HCl}$ and $100 \mu \ell$ of electrolyte into the sample. Warm the mixture to $60^{\circ} \mathrm{C}$ for $5 \mathrm{~min}$. Transfer the solution onto the filament, add $2 \mu \ell$ of platinum solution, and electrolyze for $20 \mathrm{~min}$ at $3.3 \mathrm{~V}$. The ammonium chloride electrolyte is prepared by bubbling ammonia gas through $1.5 \mathrm{M} . \mathrm{HCl}$ until a $\mathrm{pH}$ of 2.7 is obtained. The platinum solution is platinum DNS dissolved in $1.5 \mathrm{M} \mathrm{HCl}$; 


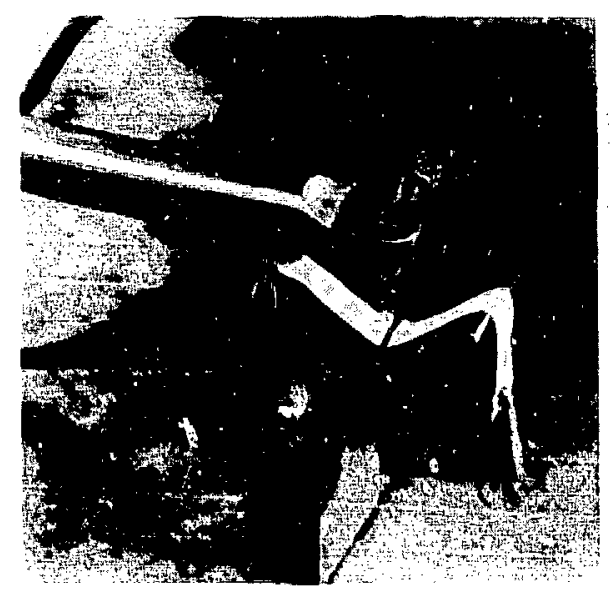

Fig. 1. Electrodeposition apparatus.
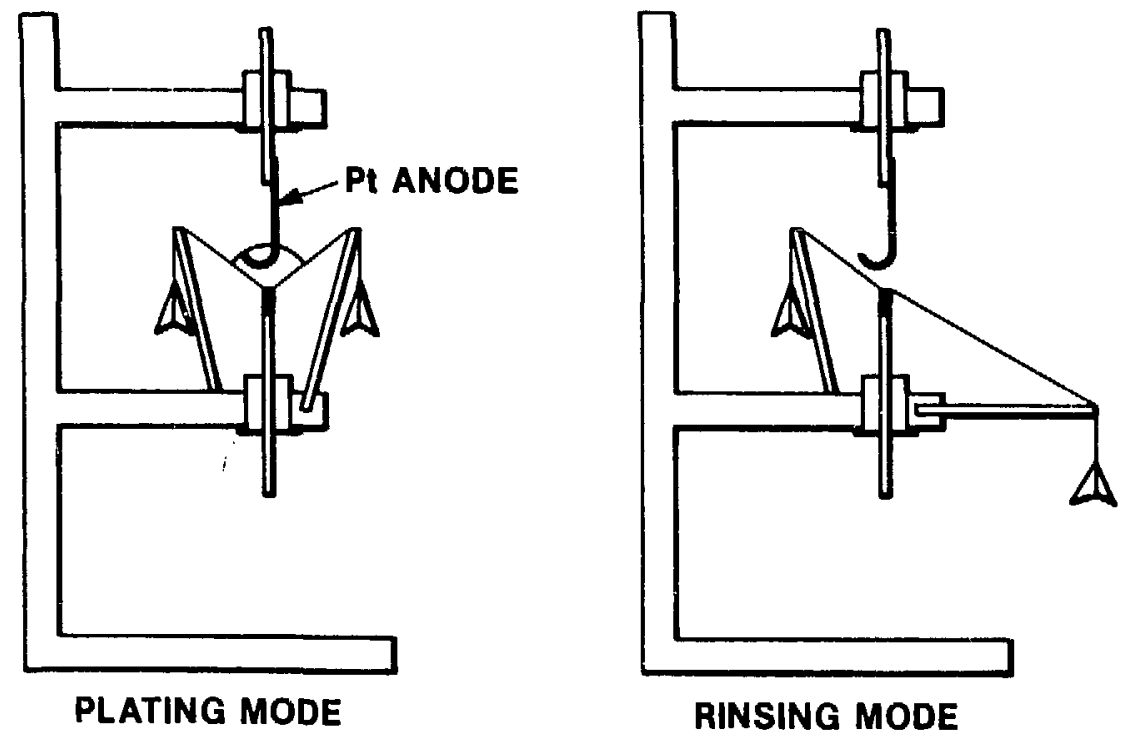

Fig. 2. Electrodeposition apparatus in (a) plating and (b) rinsing modes. 
the platinum concentration is $5 \mu \mathrm{g} / \mu \ell$. The $1.5 \mathrm{M} \mathrm{HCl}$ is added to the platinum DNS to ensure that the $\mathrm{pH}$ of the electrolyte during overplating remains below 2 . If the $\mathrm{pH}$ rises above 2 , the platinum DNS produces a nonuniform black coating that may degrade the analysis. New electrolyte and platinum DNS solution should be prepared on a periodic basis.

Add $5 \mu \ell$ of platinum solution to the electrolyte, reduce the plating voltage to $3 \mathrm{~V}$, and overplate the platinum for $20 \mathrm{~min}$. Experiments determined that these $\mathrm{pH}$ and voltage values give the best recovery yield for neptunium and the most adherent coating of platinum. An addition of $2 \mu \ell$ of platinum solution during the initial electrodeposition increases the neptunium plating efficiency to $\cong 95 \%$; the $5 \mu \ell$ of platinum solution added during the final 20 min of electrodeposition produces the optimum overplate for controlling neptunium's diffusion rate.

While the plating voltage is still applled, rinse the electrolyte from the flament with ethanol. Remove the flament from the plating apparatus, and rinse it thoroughly with de-ionized water and then glass-distilled acetone. Failure to completely rinse the electrolyte from the filament will result in a large alkali metal contamination. Dry the flament at $350^{\circ} \mathrm{C}$ by placing it under a heat lamp while passing $1.5 \mathrm{~A}$ through it for $15 \mathrm{~min}$. Examine the flament to verify that the platinum is deposited as a shiny, nonporous, uniform layer.

Scans of the sodium and potassium mass regions at $1580^{\circ} \mathrm{C}$ indicate that the alkali metal ion beams have been reduced to $\cong 1 \times 10^{6} \mathrm{cps}$. These beam intensities and the ion beam intensities from the rare-earth elements are consistent with data obtained from degassed filaments before any sample was loaded. Hydrocarbon interference is also eliminated by the electroplating processes. The scatter from metal ion beams and isobaric hydrocarbon interferences is reduced to $0.05 \mathrm{cps}$ in the neptunium mass region.

Our mass spectrometer obtains maximum stability 30 min after it is switched from the standby mode to the operational mode. Data acquisition for a neptunium sample takes $30 \mathrm{~min}$; therefore, we conducted experiments to optimize operating parameters for producing the most stable and reproducible ion beam during the data acquisition period. The optimum heating pattern is shown in Table I.

TABLE I

OPTIMUM HEATING PATTERN FOR SID FILAMENTS

\begin{tabular}{r}
$\begin{array}{r}\text { Time } \\
\text { (min) }\end{array}$ \\
\hline 0 \\
2 \\
4 \\
6 \\
8 \\
10 \\
12 \\
14 \\
20 \\
30
\end{tabular}

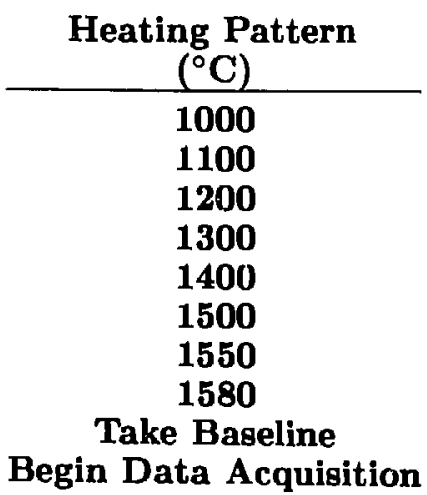




\section{DETERMINATION OF SID-SOURCE SENSITIVITY TO CHEMI-}

CAL IMPURITIES

To determine the SID source's sensitivity to chernical impurities, various salts were added to the electrolyte during neptunium deposition. The neptunium was plated by the staudard technique. Rare earths such as lanthanum, gadolinium, and samainium significantly increased the temperature at which neptunium ions formed. The neptunium ion signal followed a typical growth pattern for the first 10 to $12 \mathrm{~min}$. At that time, the beam intensity suddenly decreased. Increasing the filament temperature reestablished the neptunium ion signal; however, the beam never stabilized. In addition, a scatter background at the neptunium mass region resulted from the large rare-earth signal.

Zirconium, titanium, and tantalum also significantly increased the temperature at which neptunium ions formed. These metals ionize less efficiently than the rare earths do, and they could not be detected in the mass scans until the filament temperature was raised to $1950^{\circ} \mathrm{C}$. Neptunium ions could be formed by increasing the filament temperature, but the beam was erratic and never stabilized. Precise measurements were not possible.

Iron, chromium, nickel, and tin imparted a yellow or brown color to the platinum overplate. Although neptunium ions formed, the signal began a rapid decay after 10 to 15 min. No high-temperature run was observed; no useful measuremenis could be made.

Lead had a very deleterious effect on the SID filaments. When the filaments were heated, it became apparent that the platinum overcoat had been poisoned. As the temperature was increased, all normal background spectra as well as the neptunium ion beam were depressed by a factor of 10 to 100 .

It is obvious from these studies that the SID source requires extremely clean samples; any material that might coplate with the neptunium or platinum must be eliminated before the sample is electroplated. The following section details the chemistry that was developed to separate neptunium from Nevada Test Site debris. The dissolution procedure is designed to provide suitable samples for a variety of measurements in addition to those for mass spectrometry. ${ }^{7}$ The purification procedure produces samples that are suitable for alpha, beta, gamma, and mass spectrometric measurement techniques. The procedure has many applications in addition to those for debris analysis described here.

\section{DISSOLUTION OF NUCLEAR-TEST DEBRIS}

The elemental compositions of Nevada alluvium and tuff formations in which the nuclear detonations take place are similar to the average elemental composition of the earth's crust. Debris is fused crustal material that contains trace quantities of device material, fission products, and activation products. The successful dissolution of debris samples depends on repeated evaporations with concentrated hydrofluoric acid to convert silica and silicates to volatile silicon tetrafluoride. After the sample has been dissolved, it is stored as a $3 \mathrm{M} \mathrm{HCl}$ solution. Dissolution is performed in an exhaust hood that is equipped with a water wash-down. The step-by-step dissolution procedure is outlined here.

Place the dried and pulverized debrls sample in a Teflon beaker. Add $25 \mathrm{~m} \ell$ of fuming $\mathrm{HNO}_{3}, 100 \mathrm{m \ell}$ of $72 \% \mathrm{HClO}_{4}$, and $\mathrm{50} \mathrm{m \ell}$ of $48 \% \mathrm{HF}$. Heat the beaker on a hot plate (at a medium setting to protect the Teflon) until fumes of $\mathrm{HClO}_{4}$ begin to evolve. Cool the solution and add another $50 \mathrm{~m} \ell$ of $48 \%$ HF. Heat untll $\mathrm{HClO}_{4}$ fumes are once agaln observed. Repeat 50 -m $\ell$ addltlons untll the debris is completely dissolved. Four additions of $\mathrm{HF}$ will dissolve 5 to $10 \mathrm{~g}$ of debris; six 
treatments are needed to dissolve $15 \mathrm{~g}$. Additional perchloric acid may be added to the beaker as needed to prevent spattering. Following the finai HF addition, heat the sample for at least $15 \mathrm{~min}$ after $\mathrm{HClO}_{4}$ fumes are observed.

Cool the Tefion beaker and transfer its conterts to an 800 m $\ell$ Vycor beaker. Vycor is used instead of borosilicate glass because it is more durable and more acid resistant. Wash the Teflon with $3 \mathrm{M} \mathrm{HCl}$ and add the wash to the Vycor beaker. Add $10 \mathrm{~m} \ell$ of $72 \% \mathrm{HClO}_{4}$ to the Teflon and fume it for $5 \mathrm{~min}$. Cool and add the $\mathrm{HClO}_{4}$ to the Vycor beaker. Wash the Tefon again with $3 \mathrm{M} \mathrm{HCl}$ and add the solution to the Vycor beaker. Monitor the Tefion beaker for gamma activity to ensure that quantitative transfer has been achleved.

Swirl the Vycor beaker's contents well and heat it on a hot plate at high setting until fumes of $\mathrm{HClO}_{4}$ are observed. Fume the $\mathrm{HClO}_{4}$ for at least $30 \mathrm{~min}$, adding more $\mathrm{HClO}_{4}$ as required to prevent spattering. Flame the walis of the beaker at least once during the fuming period to ensure complete removal of ant IIF. Failure to remove the last traces of $\mathrm{HF}$ may result in a loss of neptunium. Continue heating the Vycor beaker until the volume of the sample is reduced to $50 \mathrm{ml}$. Cool the beaker's contents. Add $100 \mathrm{~m} \ell$ of $3 \mathrm{M} \mathrm{HCl}$ and warm the solution to dissolve any solids. Transfer the acid to four Vycor centrifuge tubes and centrifuge at $\mathbf{3 5 0 0}$ rpm for 2 min. Decant the supernate from the tubes back into the Teflon beaker that was used in the HF dissolution. Wash the Vycor beaker with $3 \mathrm{M} \mathrm{HCl}$ and transfer this wash into the centrifuge tubes. Warm the centrifuge tubes to dissolve the solids, centrifuge, and add the supernate to the Tefion beaker. If any precipitate remains, it is

(a) soluble crystalline salts that may be dissolved in warm $\mathrm{HCl}$,

(b) gelatinous precipitate containing $\mathrm{F}^{-}$salts that can be dissolved by additional fuming in $\mathrm{HClO}_{4}$,

(c) grains of inactive $\mathrm{SiO}_{2}$ that can be discarded at this point, or

(d) grains of active debris that were not pulverized enough to be destroyed by the HF treatments. These active grains may be dissolved by prolonged fuming with $\mathrm{HF}$ in Teflon.

Monitor the Vycor beaker and centrifuge tubeg to ensure that there has been quantitative transfer back into the Teflon.

Add $50 \mathrm{~m} \ell$ of $\mathrm{HClO}_{4}$ and $50 \mathrm{~m} \ell$ of $\mathrm{HF}$ to the Tefion beaker that contains the debris and place it on a hot plate at a medium setting until $\mathrm{HClO}_{4}$ fumes are observed. Cool the Teflon, add $50 \mathrm{~m} \ell$ of $\mathrm{HF}$, and heat to strong $\mathrm{HClO}_{4}$ fumes for at least $15 \mathrm{~min}$. Transfer the solution while it is still hot back into the $800-\mathrm{m} \ell$ Vycor beaker that was used earlier. Cool the beaker. Cool the Teflon, wash it with $3 \mathrm{M} \mathrm{HCl}$, and add the wash to the Vycor beaker. Add $10 \mathrm{ml}$ of $\mathrm{HClO}_{4}$ to the Teflon and fume for $5 \mathrm{~min}$. Pour an additional $50 \mathrm{m \ell}$ of $\mathrm{HClO}_{4}$ into the Tefion and transfer its contents to the Vycor beaker.

Fume the Vycor beaker for at least $30 \mathrm{~min}$ after all the $\mathrm{HCl}$ has boiled away. Flame the walls once or twice during the fuming. Reduce the $\mathrm{HClO}_{4}$ voiume to $50 \mathrm{~m} \ell$; stop immediately if material begins to salt out or if spattering occurs. Cool the beaker contents. Add $100 \mathrm{~m} \ell$ of $3 \mathrm{M} \mathrm{HCl}$ and warm slightly to dissolve solids. Transfer the solution to Vycor ceratrifuge tubes and centrifuge at $3500 \mathrm{rpm}$ for $2 \mathrm{~min}$. Decant the supernate through Whatman 541 filter paper into a storage bottle. If any activity remains in the beaker or the tubes, repeat the $3 \mathrm{MHCl}$ wash. If any precipitate remains in the tubes after the $3 \mathrm{M} \mathrm{HCl}$ washes, add a few $\mathrm{ml}$ of $\mathrm{HClO}_{4}$; taking cire to avoid spattering, fume the tubes over a burner and flame the walls. Add $20 \mathrm{~m} \ell \mathrm{HCl}$, centrifuge, and decant into the storage bottle through the filter paper. If the 
$\mathrm{HClO}_{4}$ treatment did not destroy the precipitate, add a few drops of $9 \mathrm{M} \mathrm{NaOH}$ and warm. Avoid boiling the $\mathrm{NaOH}$ for a prolonged period; it will etch the glass and add silicates to the solution. After treating it with $\mathrm{NaOH}$, dissolve any remaining precipitate in $20 \mathrm{~m} \ell$ of $3 \mathrm{M} \mathrm{HCl}$; warm, centrifuge, and pass it through the filter paper. Destroy the filter paper in a Vycor beaker by adding $25 \mathrm{~m} \ell$ of fumlng $\mathrm{HNO}_{3}$ and heating it. After all dry paper disappears, add $50 \mathrm{~m} \ell \mathrm{HClO}_{4}$ and heat to strong fumes. Fume until nearly dry, but avoid spattering. Flame the beaker walls once during fuming. Cool the beaker and wash its contents into a Vycor centrifuge tube with $3 M$ HCl. Cer-ifuge at $3500 \mathrm{rpm}$ for 2 min. Carefully decant the supernate into the storage botile. Add enough $3 \mathrm{M} \mathrm{HCl}$ bo dilute the concentration of the ingoing debris to $7.5 \mathrm{mg} / \mathrm{m} \ell$. Cap the bottle and place it in a water bath at $90^{\circ} \mathrm{C}$ for $12 \mathrm{~h}$ before using it.

\section{NEPTUNIUM PURIFICATION}

Neptunium is separated from macro soil constitutents, the other actinides, and fission products by a theonyltrifluoroacetone (TTA) extraction. Final purification of the sample: is accomplished on a series of anion columns. For optimum results, the purification procedure should be performed in a Class 100 clean area; the $\mathrm{HCl}, \mathrm{HNO}_{3}$, and $\mathrm{HClO}_{4}$ acids should be prepared by subboiling distillation. ${ }^{8,9}$ Ultrapure reagents must be used. All glassware, teflon, and quartz containers should be leached in aqua regia and rinsed in Type 1 reagent-grade water.

Place an aliquot of the sample in a Vycor beaker and add ${ }^{236} \mathrm{~Np}_{\mathrm{pracer}}{ }^{10} \mathrm{To}$ equilibrate the sample and spike, add 10-me of $\mathrm{HClO}_{4}$ and fume over a burner at $180^{\circ} \mathrm{C}$ or higher. The $\mathrm{HClO}_{4}$ equilibration step is omitted for untraced samples."

Cool the contents of the beaker. Add $100 \mathrm{~m} \ell$ of $1 \mathrm{M} \mathrm{HCl}$ and warm slightly to dissolve solids. Adjust the solution to a concentration of $1 \mathrm{M} \mathrm{NH} \mathrm{NH}_{2} \mathrm{OH} \cdot \mathrm{HCl}-0.25 \mathrm{M}$ $\mathrm{FeCl}_{2}$ (Ref. 11). Mix the solution and after a 5 -min reduction period, extract the neptunium for $10 \mathrm{~min}$ with an equal volume of $0.5 \mathrm{M}$ TTA-xylene. When the two phases have separated, draw off and diecard the aqueous phase. Wash the organic phase by mixing it with an equal volume of $1 \mathrm{M}$ HICl for $3 \mathrm{~min}$. Repeat the wash two more times. Iron, zirconium, cerium, and protactinium will also be extracted with the neptunium.

"If more than $4 \mathrm{~g}$ of material is needed to meet the neptunium requirements, the following fluoride precipitation should be performed after the tracer equilibration step. The sample is dissolved in $3 \mathrm{M} \mathrm{HCl}$ and enough H.F is added to make the solution $3 \mathbf{M}$ in $\mathrm{F}^{-}$concentration. Let the precipitate coagulate for $5 \mathrm{~min}$, centrifuge, and discard the supernate. Wash the precipitate with a inixture of $3 \mathbf{M ~ H C l}$ and $\mathbf{3 M ~ H F}$, centrifuge, and discard the supernate. Dissolve the fluoride precipitate in concentrated $\mathrm{HClO}_{4}$ and transfer to a Teflon beaker. Heat the Teflon beaker for at least 15 min after $\mathrm{HClO}_{4}$ fumes appear. Transfer the solution while it is still hot back into the Vycor beaker that was used earlier. Cool the Vycor beaker. Cool the Tefion beaker, wash it with $3 \mathrm{M} \mathrm{HCl}$, and add the wash to the Vycor beaker. Fume the Vycor beaker until all of the $\mathrm{HClO}_{4}$ has boiled away. Flame the walls once or twice during the fuming to remove any residual fluoride that will interfere with the subsequent TTA extraction. The fluoride precipitation removes much of the iron, cesium, zirconium, and protactinium that would be extracted with the neptunium; it also eliminates any free sulfate, phosphate, and oxalate ions. If present, these ions also have a deleterious effect on the TTA extraction. 
Strip the neptunium from the organic phase by mixing for $2 \mathrm{~min}$ with $30 \mathrm{~m} \ell$ of $8 \mathrm{M} \mathrm{HNO}$. Wash the $8 \mathrm{M} \mathrm{HNO}$ with an equal volume of $0.5 \mathrm{MTTA}$-xylene for 5 min. Discard the organic layer. At this point, the macro soil constituents sodium, potassium, magnesium, calcium, aluminum, and iron and most of the fission products have been greatly reduced. The remaining elements are $\approx 99 \%$ of the neptunium, $\approx 0.02 \%$ of the plutonium, $\approx 0.04 \%$ of the uranium, $\approx 1 \%$ of the zirconium and protactinium, and $\approx 0.03 \%$ of the niobium. Gamma-ray analysis indicates urace quantities of barium and lanthanum are also present.

To prepare the sample for loading onto an anion column, add $1 \mathrm{~m} \ell$ of $\mathrm{HClO}_{4}$ and evaporate to dryness. Cool the beaker and add $2 \mathrm{~m} \ell$ of $\mathrm{HCl}$ saturated with $\mathrm{HCl}$ gas (saturated $\mathrm{HCl}$ ) that contains 1 drop of $1 \mathrm{M} \mathrm{NH} \mathrm{NH}_{2} \mathrm{OH} \cdot \mathrm{HCl}$.

The Bio-Rad macroporous anion-exchange resin AGMP-1 (50 to 100 mesh) was warmed overnight in $5 \mathrm{M} \mathrm{HCl}$. It was washed 20 times with Type 1 reagent-grade water. The resin column was prepared in a disposable automatic pipettor tip $7 \mathrm{~cm}$ long and 5-mm i.d. (Fig. 3). These tips were leached in dilute $\mathrm{HNO}_{3}$ and soaked in Type 1 reagent-grade water. A plug of prewashed quartz wool was placed in the tip and resin was added to a depth of $2 \mathrm{~cm}$. Quartz wool must be used because glass wool contains many leachable impurities. The column was conditioned by three $1-\mathrm{m} \ell$ washes with Type 1 reagent-grade water and one $1-\mathrm{m} t$ saturated $\mathrm{HCl}-\mathrm{NH}_{2} \mathrm{OH} \cdot \mathrm{HCl}$ wash.

Load the saturated $\mathrm{HCl}-\mathrm{NH}_{2} \mathrm{OH} \cdot \mathrm{HCl}$ contalning the neptunlum onto the anlon column. Wash the beaker that contained the neptunlum wlth $1 \mathrm{~m} \ell$ of the saturated $\mathrm{HCl}-\mathrm{NH}_{2} \mathrm{OH} \cdot \mathrm{HCl}$ solution and add the wash to the resin column. Discard the eluate. Wash the column with $5 \mathrm{~m} \ell$ of saturated $\mathrm{HCl}$ contalning $0.06 \mathrm{M} \mathrm{HF}$ (Ref. 12). This removes most of the residual zirconium from the sample. Rinse the column with three successlve addltlons of 9 drops of $\mathrm{HI}$-saturated $\mathrm{HCl}$ reagent mixture that is 1 to 9 by volume, ultrapure, nonstabllyed $\sim 48 \% \mathrm{HI}$ and saturated HCl. Ultrapure, nonstabilized $\mathrm{HI}$ must be used; the $\mathrm{H}_{3} \mathrm{PO}_{3}$ stabilizer and impurities in reagent-grade $\mathrm{HI}$ would contaminate the sample. The $\mathrm{HI}$-saturated $\mathrm{HCl}$ removes the last traces of plutonium from the anion column. Elute the neptunium Into a $30-\mathrm{m} \ell$ Teflon beaker with $3 \mathrm{~m} \ell$ of 6.5M HCl-0.004M HF. Evaporate the solution to dryness. The majority of the iron, uranium, and niobium is retained on the column.

It is necessary to use a second macroporous anion-exchange resin column to achiev the additional levels of purity required for pulse-counting mass spectrometry. To prepare the sample for treatment on the macroporous anion-exchange column, dissolve it in $1 \mathrm{~m} \ell$ of saturated $\mathrm{HCl}$. This column is identical to the firsi column; condition it by three $1-\mathrm{m} \ell$ washes with Type 1 reagent-grade water and a $1-m \ell$ wash with saturated $\mathbf{H C l}$.

Load he neptunium solution on the macroporous anion column. Wash with 1 $\mathrm{m} \ell$ of saturated $\mathrm{HCl}$. Elute the neptunium with $5 \mathrm{~m} \ell$ of ultrapure, nonstabilized $47 \% \mathrm{HBr}$ into a clean quartz test tube. Using $47 \% \mathrm{HBr}$ effects a final iron separation and reduces the amount of zirconium, niobium, and uranium remaining in the sample.

Evaporate tice $\mathrm{HBr}$ solution to dryness in a heating block. Destroy the traces of HBr and organic material eluted from the resin by adding 3 drops of concentrated $\mathrm{HNO}_{3}$ and 3 drops of concentrated $\mathrm{HClO}_{4}$. Heat at $130^{\circ} \mathrm{C}$ for $1 \mathrm{~h}$. Raise the temperature of the heatlng block to $180^{\circ} \mathrm{C}$ and evaporate the sample to dryness. The sample is now ready for analysis. Typical chemical yields for the purification procedure are 50 to $80 \%$. 

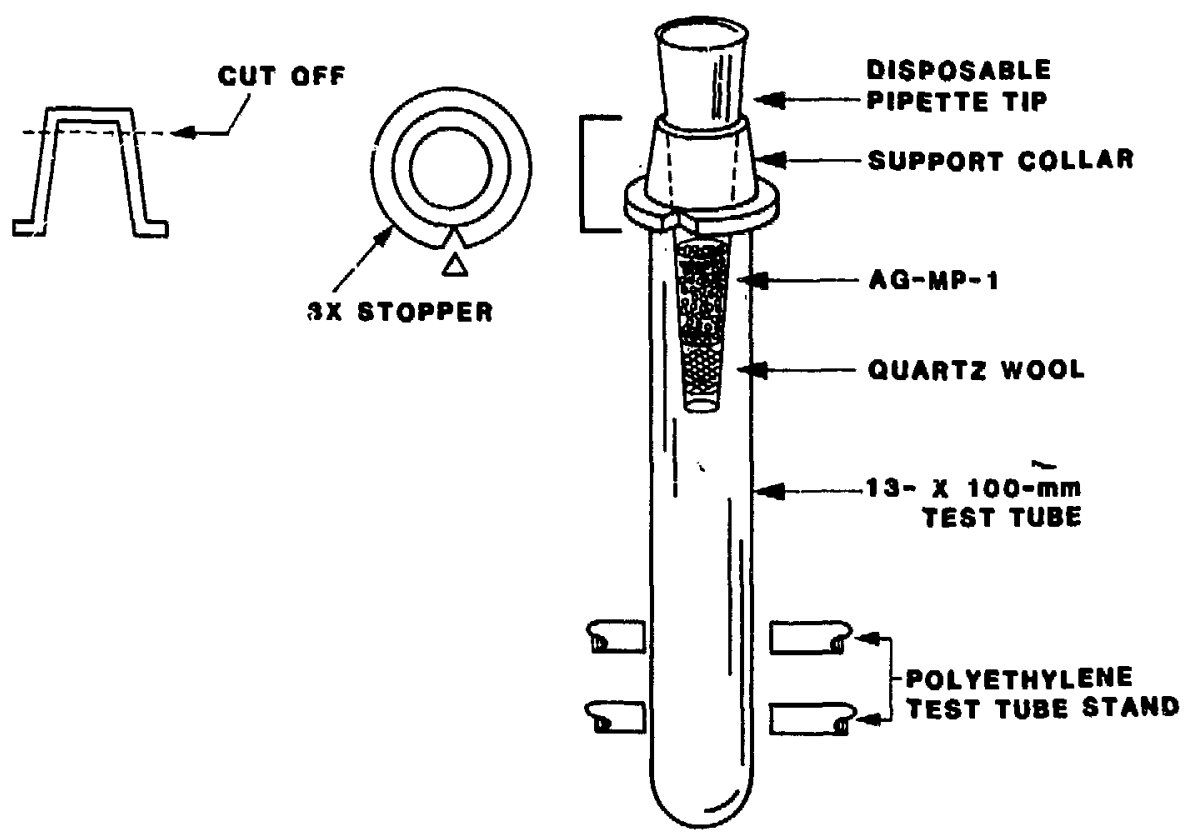

Fig. 3. Macroporous anion-exchange column.

\section{ANALYSIS OF TEST DEBRIS USING THE SID SOURCE}

The neptunium in test debris is contained in a complex chemical matrix, and no two samples of test debris are identical in chemical composition. Therefore, one would expect that extraneous materials occasionally "leak" during the separation and purification chemistry. These impurities increase the uncertainty of the mass spectrometric measurements.

To determine the suitability of the SID source and the effectiveness of the chemical separations procedure for debris analysis, a series of analyses were performed. Table II summarizes the recovery and decontamination efficiencies obtained in these analyses. Table III summarizes our analy ïical capabilities. 
TABLE II

RECOVERY AND DECONTAMINATION OF NEPTUNIUM

\begin{tabular}{l}
\multicolumn{1}{c}{ Element } \\
\hline Neptunium \\
Niobium \\
Plutonium \\
Zirconium \\
Uranium \\
Iron
\end{tabular}

\author{
Amount \\ Recovered \\ 50 to 80 \\ 0.000 .1 \\ 0.00008 \\ 0.00006 \\ 0.00004 \\ 0.6000004
}

TABLE III

SUMMARY OF ANALYTICAL CAPABILITIES FOR NEPTUNIUM

\author{
Soil (maximum sample processed) \\ Tissue (maximum sample processed) \\ Typical amount of neptunium loaded on filament \\ Ionization temperature \\ Ionization efficiency \\ Detection limit \\ Precigion (95\% confidence level)
}

\author{
$100 \mathrm{~g}$ \\ $2000 \mathrm{~g}$ \\ $0.1 \mathrm{ng}$ \\ $1580^{\circ} \mathrm{C}$ \\ $1.0 \%$ \\ $1 \times 10^{5} \mathrm{~atm}$ \\ $0.15 \%$
}

\section{OTHER APPLICATIONS FOR THE SID FILAMENT}

The platinum-overcoated SID filaments have been used to measure both plutonium and neptunium in soil and tissue samples. The ${ }^{237} \mathrm{~Np} /{ }^{239} \mathrm{Pu}$ atom ratio in global fallout is 0.7 ; the ${ }^{237} \mathrm{~Np} /{ }^{239} \mathrm{Pu}$ atom ratio in lung and liver tissue of individuals exposed to global fallout is 0.04 (Refs. 13 and 14, respectively). These results imply that neptunium is preferentially excreted from the lungs and liver relative to plutonium. It would be interesting to measure the neptunium-to-plutonium ratio in bone tissue. 


\section{REFERENCES}

1. J. R. Rec, W. G. Myers, and F. A. White, "Diffusion Controlled, Thermal Ionization Source for Mass Spectrometric Analysis of Trace Metals," Anal. Chem. 54 No. 9, 1243-1247 (1974).

2. R. E. Perrin, D. J. Rokop, J. H. Cappis, and W. R. Shields, "Electro-Deposition as a Sample Mounting Technique for U and Pu Isotopic Analysis," Am. Soc. Mass Spectrom., Twenty-Ninth Annual Conf., Mass Spectrometry and Allied Topics, Minneapolis, Minnesota, May 24-29, 1981, pp. 422-423.

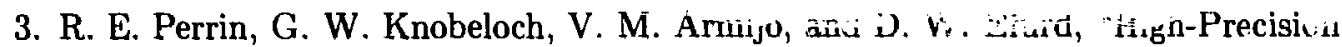
Isotopic Analysis of Nanogram Quantities of Plutonium," Los Alamos National Laboratory report LA-10013-MS (June 1984).

4. R. E. Perrin, G. W. Knobeloch, V. M. Armijo, and D. W. Efurd, "Isotopic Analysis of Nanogram Quantities of Plutonium by Using a SID Ionization Source," Int. J. Mass Spec. Ion Phys. 64, 17-24 (1985).

5. W. R. Shields, Ed., "Analytical Mass Spectrometry Section: Summary of Activities July 1966 to June 1967," NBS Technical Note No. 426 (1967).

6. R. W. Shideler, "A High Speed Non-Overloading Discriminator for High Accuracy Pulse Counting," Int. J. Mass Spec. Ion Phys. 21, 213-219 (1976).

7. G. W. Knobeloch, "The Dissolution of Dirt Samples," in "Collected Radiochemical Procedures (Radiochemistry Group CNC-11)," Los Alamos Scientific Laboratory report LA-1721, 4th Ed. (April 1975).

8. J. R. Moody, "NBS Clean Laboratories for Trace Element Analysis," Anal. Chem. 54 No. 13, 1358A-1376A (1982).

9. E. C. Kuehner, R. Alverez, P. F. Paulsen, and T. J. Murphy, "Production and Analysis of Special High-Purity Acids Purified by Sub-Boiling Distillation," Anal. Chem. 44, 2050-2056 (1972).

10. J. H. Landrum, M. Linder, and N. Jones, "A Mass Spectrometric Method for Determination of Subnanogram Quantities of Neptuniurn-237," Anal. Chem. 41, 840-842 (1969).

11. F. L. Moore, "Separation and Determination of Neptunium by Liquid-Liquid Extraction," Anal. Chem. 29, 941-944 (1957).

12. L. Wish, "Quantitative Radiocheinical Analysis by Ion Exchange, Anion Exchange Behavior in Mixed Acid Solutions and Development of a Sequential Separation Scheme," Anal. Chem. 31 No. 3, 326-330 (1959). 
13. D. W. Efurd, G. W. Knobeioch, R. E. Perrin, and D. W. Barr, "An Estimate of ${ }^{237} \mathrm{~Np}$ Production During Atmospheric Testing," Health Physics 47, 786-787 (1984).

14. D. W. Efurd and R. E. Perrin, "Neptunium-237 in Human Autopsy Tissues," in "Isotope and Nuclear Chemistr, Division Annual Report FY 1984," Los Alamos National Laboratory report LA-10366-PR (April 1985), p. 47. 